\title{
Open access, predatory publishing and peer-review
}

Fernando FERNANDEZ-LLIMOS.

Keywords: Publishing; Access to Information; Peer Review, Research; Codes of Ethics; Cooperative Behavior

In recent years, scholarly publishing faced a new paradigm regarding the accessibility: the open access movement. "If an article is "Open Access" it means that it can be freely accessed by anyone in the world using an internet connection". ${ }^{1}$ The Budapest Open Access Initiative states: "By "open access" to this literature, we mean its free availability on the public internet, permitting any users to read, download, copy, distribute, print, search, or link to the full texts of these articles, crawl them for indexing, pass them as data to software, or use them for any other lawful purpose, without financial, legal, or technical barriers other than those inseparable from gaining access to the internet itself". ${ }^{2}$ Some researchers may have never been concerned about this topic. It obviously means that they are affiliated with a rich institution from a rich country. There are few things more discouraging for a researcher than performing a literature search, retrieving a list of potentially interesting articles, and not being able to access many of them because one's library does not subscribe those journals. And this lack of access will increase, even in major Universities from rich countries ${ }^{3}$, where the average cost of subscription reached 12,000 USD per faculty member more than 10 years ago. ${ }^{4}$

Administrations are regulating the access to the results of publicly funded researches by using these open access systems: initially, through a voluntary Public Access Policy and then making it mandatory. ${ }^{5}$ The European Union slowly followed a similar policy, initiated at the Seventh Framework Programme. ${ }^{6}$ Many other institutions and countries are following this movement. ${ }^{7}$ PubMed Central is a free archive of biomedical and life sciences journal literature at the U.S. National Institutes of Health's National Library of Medicine $(\mathrm{NIH} / \mathrm{NLM})$, and it has the legislative mandate to collect and preserve the biomedical literature. ${ }^{8}$

The open access movement led to the emergence of business-oriented publishers aiming to make money within this niche. Thus, the authors' pay system emerged and new journals were born. Traditional subscription journals created their open access system by allowing free access through the Internet to some articles whose authors had paid a certain amount of money. The amounts due to open the access to an article, whether in an open access journal or by opening the access in a subscription-based journal, are not cheap. ${ }^{9}$

Soon, there was a concern that some of these publishers may have been more focused on making money out of the open access movement, than in contributing to the diffusion of scientific knowledge. The names "Predatory Open-Access Publishers" and "predatory scholarly open-access journals" are used to describe these questionable publishers and journals. Lists of predatory publishers and predatory journals were created based on specific criteria. ${ }^{10} \mathrm{~A}$ recent study shocked the open access people and the scientific community. ${ }^{11}$ Although, at least in theory, open access should not have any influence on the quality of the peer-review process1, Bohannon demonstrated that this assumption is not real, and that a clearly marked geographic distribution of predatory publishers does exist.

But we should keep in mind that peer-review pitfalls have always existed, even in highly prestigious, expensive subscription journals. A lot of examples can be mentioned, but probably one stands out because of the journal involved and the research area: the two Hwang's articles, published in Science in 2005 and 2006, pretending having cloned human cells [purposively not included in the references] retracted by journal's editors after internal investigations. ${ }^{12}$ Perhaps because of the difficulty of identifying frauds, specifically fabricated data, JAMA editors stated in 1989 "Editors of peer-reviewed journals have relationships based on trust with authors, readers, owners, editorial board members, reviewers, funding agencies, institutions, students, advertisers, the media, and the public at large". ${ }^{13}$ This disclaimer seems to be a declaration of the peer-review process limitations. On the other hand, peer-review process in prestigious journals has inappropriately rejected articles. A well know example is the rejection of the letter submitted in 1937 by Hideki Yukawa to Physic Rev regarding some sub-atomic forces, with very explicit reviewer's comments destroying his thoughts. In 1949, Yukawa was awarded the Nobel Price "for his prediction of the existence of mesons on the basis of theoretical work on nuclear forces". ${ }^{14}$

*Fernando FERNANDEZ-LLIMOS. PhD, PharmD, MBA. Editor-in-chief, Pharmacy Practice. Institute for Medicines Research (iMed.ULisboa), Department of Social Pharmacy, Faculty of Pharmacy, Universidade de Lisboa. Lisbon (Portugal). 
Let us think in a different way of scholarly publishing: the collaborative publishing. Although this name is used for book publishing, scientific journals may consider its principles, while keeping the highest quality standards in their editorial process. After appearing the journal management and publishing system with freeware licensing, such as Open Journal Systems (OJS), one of the major costs in electronic journals published by non-profit institutions is the peer-review process. Although peer-reviewers collaborate on a no-cost basis, the process itself is highly time and administrative resources consuming.

Selection of peer-reviewers should ensure the adequacy of the reviewer, not only in terms of absence of conflict of interests, but also in reviewer's expertise in the specific area of the manuscript evaluated. Traditional methods of reviewers' selection are based on the areas of interest and skills declared by the reviewers when they apply to join the journal's list of peer reviewers. In these methods, the journal waits for reviewers' applications after a 'call for reviewers'. Obviously, the editors assess the competence of the candidates for reviewers through several methods, including their publication track. However, this method may have two limitations: a) reviewers may have assigned themselves with a competence too optimistically, and b) editors have only a restricted list of potential reviewers to assign manuscripts.

An active selection method for reviewers consists in a literature search using the keywords assigned to the manuscript, in order to retrieve recently published articles within a very similar theme. This method allows identifying authors that have recently performed some research in the same area of the manuscript received. No matter if these potential reviewers had previously showed their interest by applying for the journal's reviewers list, they are requested to collaborate as peer-reviewers of that manuscript. Although this method may be more appropriate than the list of reviewers to identify authors recently in a specific research, it is more time and administrative resources consumption due to a low response and acceptance rate.

In the past few months, Pharmacy Practice adopted the OJS as journal management and publishing system, has been included in PubMed Central, and has implemented an active selecting method for peer-reviewers. Articles published in 2013 had a 182-day period from their initial submission to the final decision of acceptance, including the time given to the authors for modification requested by reviewers. All the articles were included in the first issue published after their acceptance. In order to maintain, and even reduce this delay, which is one of the shortest among pharmacy practice journals, we kindly ask the authors in this area to make an effort and accept the challenge of a collaborative publishing. Pharmacy Practice declares its commitment with publishing an independent scientific journal, following the standards of the Recommendations for the Conduct, Reporting, Editing, and Publication of Scholarly work in Medical Journals of the International Committee of Medical Journal Editors, and the Code of Conduct of the Committee on Publication Ethics. ${ }^{15,16}$

\section{References}

1. What is Open Access? Available at: http://www.sherpa.ac.uk/guidance/authors.html\#whatoa (Accessed March 9, 2014).

2. Budapest Open Access Initiative. Available at: http://www.budapestopenaccessinitiative.org/read (Accessed March 9, 2014).

3. The Harvard Library. Major Periodical Subscriptions Cannot Be Sustained. Available at: http://isites.harvard.edu/icb/icb.do?keyword=k77982\&tabgroupid=icb.tabgroup143448 (Accessed March 9, 2014).

4. Odlyzko A. The Economics of Electronic Journals. First Monday. 1997;2(4):542. doi: 10.5210/fm.v2i8.542

5. NIH Public Access Policy Details. Available at: http://publicaccess.nih.gov/policy.htm (Accessed March 9, 2014).

6. Open Access in FP7. Available at: http://ec.europa.eu/research/sciencesociety/index.cfm?fuseaction=public.topic\&id=1300\&lang=1 (Aceessed March 9, 2014).

7. OA statements and declarations - links and resources. Available at: http://sparceurope.org/statements/ (Accessed March 9, 2014)

8. PMC Overview. Available at: http://www.ncbi.nlm.nih.gov/pmc/about/intro/ (Accessed March 9, 2014).

9. Comparison of BioMed Central's article-processing charges with those of other publishers. Available at: http://www.biomedcentral.com/about/apccomparison/ (Aceessed March 9, 2014).

10. Criteria for Determining Predatory Open-Access Publishers (2nd edition). http://scholarlyoa.com/2012/11/30/criteria-fordetermining-predatory-open-access-publishers-2nd-edition/ (Accessed March 9, 2014).

11. Bohannon J. Who's afraid of peer review? Science. 2013;342(6154):60-65. doi: 10.1126/science.342.6154.60

12. Kennedy D. Editorial retraction. Science. 2006;311(5759):335.

13. Lundberg GD, Flanagin A. New requirements for authors: signed statements of authorship responsibility and financial disclosure. JAMA. 1989;262(14):2003-2004.

14. The Nobel Prize in Physics 1949. Available at: http://www.nobelprize.org/nobel_prizes/physics/laureates/1949/ (Accessed March 9, 2014).

15. International Committee of Medical Journal Editors. Recommendations for the Conduct, Reporting, Editing, and Publication of Scholarly Work in Medical Journals. Available at: http://www.icmje.org/icmje-recommendations.pdf (Accessed March 9, 2014).

16. Committee on Publication Ethics. Available at: http://publicationethics.org/ (Accessed March 9, 2014) 